\title{
Smear Layer Removal and Canal Cleanliness Using Different Irrigation Systems (EndoActivator, EndoVac, and Passive Ultrasonic Irrigation): Field Emission Scanning Electron Microscopic Evaluation in an In Vitro Study
}

\author{
Manuele Mancini, DDS, ${ }^{*}$ Loredana Cerroni, DDS, ${ }^{\dagger}$ Lorenzo Iorio, DDS, * \\ Emiliano Armellin, DDS, ${ }^{\dagger}$ Gabriele Conte, DDS, ${ }^{*}$ and Luigi Cianconi, MD, DDS *
}

\begin{abstract}
Ahstract
Introduction: The purpose of this study was to evaluate the effectiveness of different irrigating methods in removing the smear layer at $1,3,5$, and $8 \mathrm{~mm}$ from the apex of endodontic canals. Methods: Sixty-five extracted single-rooted human mandibular premolars were decoronated to a standardized length of $16 \mathrm{~mm}$. Specimens were shaped to ProTaper F4 (Dentsply Maillefer, Ballaigues, Switzerland) and irrigated with 5.25\% $\mathrm{NaOCl}$ at $37^{\circ} \mathrm{C}$. Teeth were divided into 5 groups (2 control groups $[n=10]$ and 3 test groups $[n=15]$ ) according to the final irrigant activation/delivering technique (ie, sonic irrigation, passive ultrasonic irrigation [PUI], or apical negative pressure). Root canals were then split longitudinally and observed by field emission scanning electron microscopy. The presence of debris and a smear layer at 1, 3, 5, and $8 \mathrm{~mm}$ from the apex was evaluated. Scores were analyzed by KruskalWallis and Mann-Whitney $U$ tests. Results: The EndoActivator System (Dentsply Tulsa Dental Specialties, Tulsa, OK) was significantly more efficient than PUI and the control groups in removing the smear layer at 3, 5, and $8 \mathrm{~mm}$ from the apex. The EndoVac System (Discus Dental, Culver City, CA) removed statistically significantly more smear layer than all groups at 1, 3, 5 , and $8 \mathrm{~mm}$ from the apex. At 5 and $8 \mathrm{~mm}$ from the apex, PUI and the EndoVac did not differ statistically significantly, but both performed statistically better than the control groups. Conclusions: In our study, none of the activation/delivery systems completely removed the smear layer from the endodontic dentine walls; nevertheless, the EndoActivator and EndoVac showed the best results at 3,5, and $8 \mathrm{~mm}$ (EndoActivator) and 1, 3, 5, and $8 \mathrm{~mm}$ (EndoVac) from the apex. (J Endod 2013;39:1456-1460)
\end{abstract}

\section{Key Words}

EndoActivator System, EndoVac System, field emission scanning electron microscopy, irrigant activation, passive ultrasonic irrigation, smear layer

D ebridement of the root canal system is essential to endodontic success $(1,2)$. Shaping of root canals creates a smear layer that consists of organic and inorganic substances, including fragments of odontoblastic processes, microorganisms, and necrotic materials $(3,4)$. The smear layer has been shown to prevent the penetration of intracanal disinfectants (5) and sealers (6) into the dentinal tubules, which may result in compromising the seal of the root filling $(7,8)$. Many irrigating solutions have been used to reduce residual debris, necrotic tissue, and bacteria as well as the smear layer formed by the mechanical instrumentation of the root canal system $(5,9)$. Sodium hypochlorite $(\mathrm{NaOCl})$ has become the most widely used irrigating solution in endodontics (10). The alternate use of $\mathrm{NaOCl}$, a deproteinizing agent, and EDTA, a calcium-chelating agent, has been recommended for the efficient removal of the smear layer $(4,11)$. To improve cleanliness, irrigants should be in contact with root canals (9). The traditional needle irrigation technique delivers solutions no more than $0-1.1 \mathrm{~mm}$ beyond the needle tip (12). This is insufficient for complete cleaning of the complex anatomy of the root canal system (lateral canals, isthmuses, fins, and accessory canals) (13). A vapor lock that results in trapped air in the apical third of root canals has also been considered because it might hinder the exchange of irrigants and affect their debridement efficacy (14). Different devices for irrigation delivery have been proposed to increase the flow and distribution of irrigating solutions within the root canal system (15), especially at the apical third level. The EndoActivator System (EA) (Dentsply Tulsa Dental Specialties, Tulsa, OK) is a sonically driven irrigant activation system designed to produce vigorous intracanal fluid agitation that has been shown to increase the efficacy of irrigation better than traditional needle irrigation (16). It comprises a portable handpiece and 3 types of disposable flexible polymer tips of different sizes that do not cut root dentin. Passive ultrasonic irrigation (PUI), first described by Weller et al (17), uses a stainless steel file to activate the irrigant in the canal (18). PUI is able to disrupt the endodontic biofilm, facilitating better penetration of irrigants throughout the endodontic dentinal walls $(15,18)$. The EndoVac System (EV) (Discus Dental, Culver City, CA) is an apical negative pressure irrigation device that is designed to drain irrigating solution at the apical third level of the canal system and to remove debris via a negative pressure mechanism (19).

From the Departments of *Restorative Dentistry and Endodontics and 'Dental Materials, University of Rome "Tor Vergata," Rome, Italy.

Address requests for reprints to Dr Manuele Mancini, Via Tuscolana 58/64, 00182 Rome, Italy. E-mail address: manuele.mancini@tiscali.it 0099-2399/\$ - see front matter

Copyright (c) 2013 American Association of Endodontists.

http://dx.doi.org/10.1016/j.joen.2013.07.028 
TABLE 1. Experimental Groups and Protocols

\begin{tabular}{|c|c|c|c|c|}
\hline Group name & $n$ & Shaping & Activation & Protocol \\
\hline Negative control & 10 & No & No & - \\
\hline Positive control & 10 & Yes & No & - \\
\hline PUI & 15 & Yes & Yes: PUI & $\begin{array}{l}\text { Final rinse with } 5 \mathrm{~mL} 5.25 \% \mathrm{NaOCl} 37^{\circ} \mathrm{C} \text { activated with PUI; a \#.15 K-file (Dentsply } \\
\text { Maillefer) was used driven by an ultrasonic device (MiniEndo II; SybronEndo, West } \\
\text { Collins, Orange, CA) with power set at } 5 \text { for } 1 \text { minute at } 1 \mathrm{~mm} \text { from the WL }\end{array}$ \\
\hline EA & 15 & Yes & Yes: EA & $\begin{array}{l}\text { Final rinse with } 5 \mathrm{~mL} 5.25 \% \mathrm{NaOCl} 37^{\circ} \mathrm{C} \text { activated for } 1 \text { minute with the EA system with } \\
\text { a } 15 / .02 \text { point at } 2 \mathrm{~mm} \text { from the WL }\end{array}$ \\
\hline EV & 15 & Yes & Yes: EV & $\begin{array}{l}\text { Final rinse with } 5 \mathrm{~mL} 5.25 \% \mathrm{NaOCl} 37^{\circ} \mathrm{C} \text { activated according to manufacturer's } \\
\text { protocol for the } \mathrm{EV} \text {; to standardize the draining procedure, a rubber stop was } \\
\text { placed } 9 \mathrm{~mm} \text { from the tip of the macrocannula, used } 30 \text { seconds with } 5.25 \% \mathrm{NaOCl} \\
37^{\circ} \mathrm{C} \text {, plus } 30 \text { seconds of soaking in } \mathrm{NaOCl} \text {, plus } 3 \mathrm{cycles} \text { of irrigation using } \\
\text { microcannula: (1) } 30 \text { seconds with } 5.25 \% \mathrm{NaOCl} 37^{\circ} \mathrm{C}+30 \text { seconds soak } \mathrm{NaOCl} \text { in } \\
\text { the channel, (2) } 1 \text { min } 17 \% \text { EDTA }+1 \text { min by soaking, and (3) } 1 \text { min with } 5.25 \% \\
\mathrm{NaOCl} 37^{\circ} \mathrm{C}+1 \text { min of soaking in } 5.25 \% \mathrm{NaOCl} 37^{\circ} \mathrm{C}\end{array}$ \\
\hline
\end{tabular}

EA, EndoActivator System; EV, EndoVac System; PUI, passive ultrasonic irrigation.

The EV has been shown to introduce a higher flow of irrigant and produce better debridement compared with that achieved by needle irrigation (20). Additionally, the EV has been shown to extrude less irrigant in the periapical tissues, thus reducing accidental extrusion of NaOCl (21). There is a scarcity of data evaluating debris removal with similar experimental protocols; therefore, the aim of this study was to evaluate smear layer removal and endodontic wall cleanliness after different irrigant activation regimens.

\section{Root Ganal Preparation}

\section{Materials and Methods}

Sixty-five single-rooted mandibular premolars extracted for orthodontic therapeutic indications were randomly selected from the same age group (15- to 25-year-old patients) with the approval of the Ethics in Research Committee of the Centre of Health Sciences of the University of Rome "Tor Vergata," Rome, Italy. Teeth were devoid of caries, cracks, endodontic treatments, and restorations. Only teeth with intact and mature root apices and roots longer than $14 \mathrm{~mm}$ were selected. Teeth were then x-rayed buccolingually and mesiodistally. Teeth with root canal curvatures greater than $20^{\circ}$ or calcified root canals were excluded. After extraction, teeth were stored in $2 \%$ thymol solution at room temperature and used within 1 week. Inclusion and exclusion criteria were verified under a $20 \times$ magnification laboratory microscope (Stemi DV4 Spot; Carl Zeiss, Oberkochen, Germany). After the access cavity was created, a \#10 K-file (Dentsply Maillefer, Ballaigues, Switzerland) was inserted into the canal until the instrument tip was barely visible at the apical foramen. The root lengths were standardized to $16 \mathrm{~mm}$ by decoronation of the tooth perpendicular to the long axis by means of a high-speed, water-cooled diamond disc. To simulate clinical conditions, apices were sealed with hot glue, and to prevent the glue from entering the canal, a \#10 K-file was inserted before the apex was sealed. The Pro-Train (Simit Dental, Mantova, Italy) was used during the experimental protocol to standardize the procedures for tooth preparation. Specimens were randomly divided into 2 control groups $(n=10)$ and 3 experimental groups $(n=15)$. Except for the negative control group, groups were shaped by means of ProTaper Ni-Ti rotary instruments (Dentsply Maillefer) according to the manufacturer's instructions until the ProTaper F 4 file reached the working length (WL). Each instrument was used to shape only 4 specimens. After each instrumentation and before the next, canals were rinsed with $3 \mathrm{~mL}$ $5.25 \% \mathrm{NaOCl}$ at $37^{\circ} \mathrm{C}$ (Chematek SpA, Rome, Italy). The apical patency was checked after each instrument with a \#10 K-file. Each group was then irrigated with $17 \%$ EDTA (Chematek SpA) and left in the canal for 1 minute before being rinsed with $3 \mathrm{~mL} 5.25 \% \mathrm{NaOCl}$ at $37^{\circ} \mathrm{C}$.
Finally, $5.25 \% \mathrm{NaOCl}$ at $37^{\circ} \mathrm{C}$ was activated/delivered with different methods (Table 1). Irrigating solutions were delivered by means of a 30-G syringe needle (NaviTip; Ultradent, South Jordan, UT) inserted deeply at $1 \mathrm{~mm}$ from the WL. All specimens were then irrigated with $5 \mathrm{~mL}$ distilled water and dried with sterile paper points.

\section{Specimen Preparation}

Field emission scanning electron microscopy was used to evaluate endodontic smear layer removal from the instrumented root canals. To facilitate fracture into halves, all roots were grooved longitudinally on the external surface with a diamond disc without penetration into the root canals. The roots were then split into halves with a chisel with a ProTaper F4 gutta-percha cone in the root canal to limit tooth fragments covering endodontic canal walls. For each root, the half containing the most visible part of the endodontic wall was conserved and coded. The coded specimens were secured on metal stubs, desiccated, and viewed with field emission scanning electron microscopy (SUPRA 35; Carl Zeiss SMT, Oberkochen, Germany). The main operating parameters of the instrument were $5 \mathrm{KeV}$ as gun voltage and a working distance of about $11 \mu \mathrm{m}$; both parameters were chosen to avoid an excessive charging of the specimens. The detector used was the "second electron detector" (SE2) because the interest was focused mainly on the topography of the canal structure. Five micrographs for each tooth were taken in the same positions inside the canal (tip of the tooth, $1 \mathrm{~mm}, 3 \mathrm{~mm}, 5$ $\mathrm{mm}$, and $8 \mathrm{~mm}$ from the apex) at 3 different magnifications $(300 \times$, $1,000 \times$, and $3,000 \times)$.

\section{Field Emission Scanning Electron Microscopic Evaluation}

Cleanliness was evaluated by micrographs taken at $1,3,5$, and 8 $\mathrm{mm}$ from the apex at a $1,000 \times$ magnification (Fig. 1). Two observers performed blind evaluation independently after examining 20 specimens for calibration purposes. Intra- and interexaminer reliability for field emission scanning electron microscopic assessment was verified by the kappa test. Cleanliness was evaluated according to a 5-score index system codified by Hulsmann et al (22), which measured the presence, quantity, and distribution of the smear layer as follows: score $1=$ no smear layer (dentinal tubules open), score $2=$ small amount of smear layer (some dentinal tubules open), score 3 = homogenous smear layer covering the root canal wall (only a few dentinal tubules open), score $4=$ complete root canal wall covered by a homogenous smear layer (no open dentinal tubules), and score $5=$ heavy nonhomogenous smear layer covering the complete root canal wall. Data were analyzed using Kruskal-Wallis and Mann-Whitney $U$ tests. 


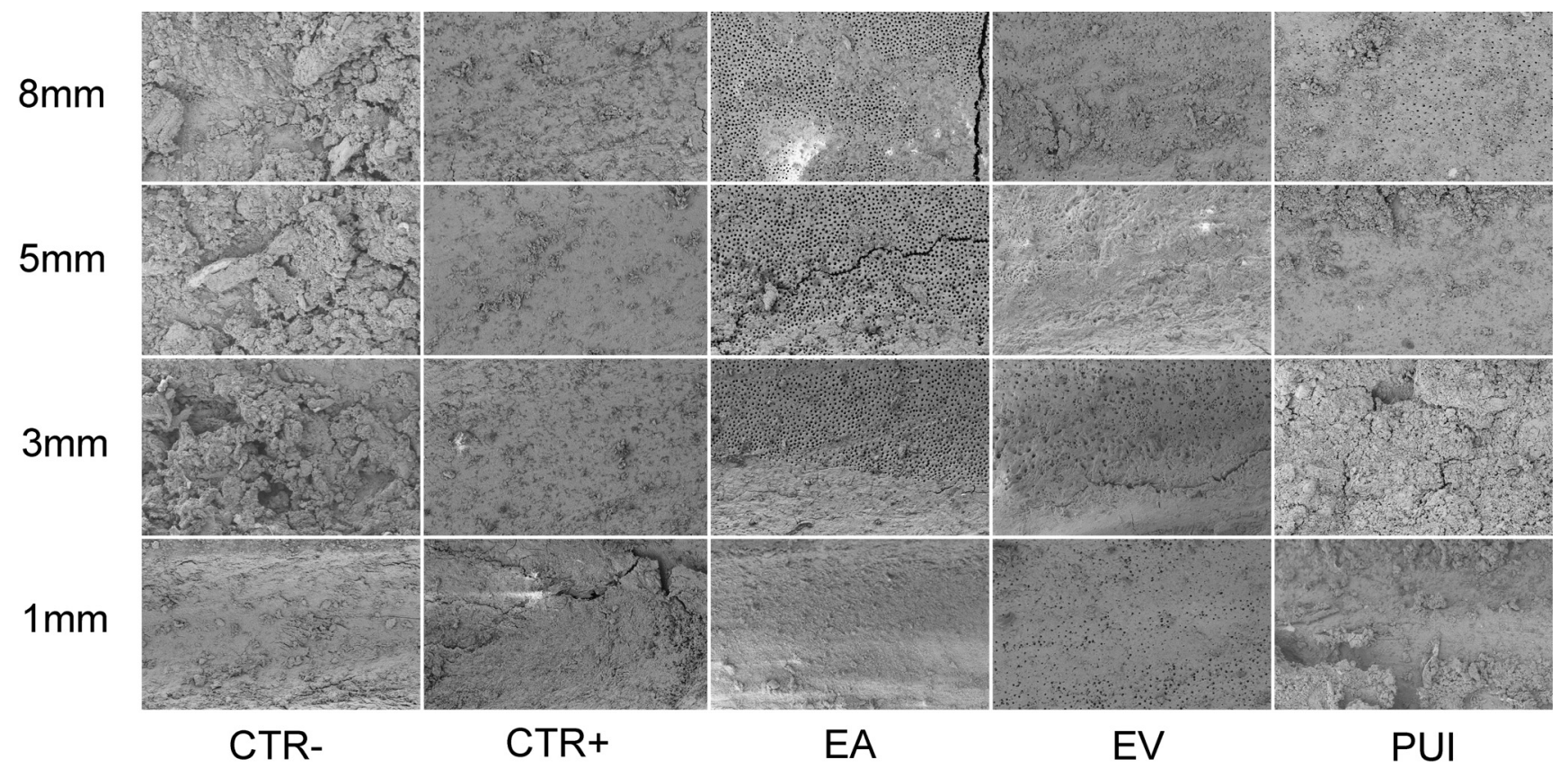

Figure 1. Field emission scanning electron microscopic images at $1,3,5$, and $8 \mathrm{~mm}$ from the apex $(1,000 \times)$.

Bonferroni, Scheffé, and Sidak multiple comparison tests were used; $P$ values were computed and compared with statistical significance at the $P=.05$ level. The data were analyzed with the statistical software STATA (STATA Statistical Software Release 12.1; Stata Corp, College Station, TX).

\section{Results}

Kappa test results, with a significance set at 0.5 , showed good intra- and interexaminer agreement, with values ranging from 0.90 and above for the different groups. On analysis of the field emission scanning electron microscopic photomicrographs, cleanliness was evaluated, and the results for the various groups are reported in Table 2 as the mean score and standard deviation. At $1 \mathrm{~mm}$ from the apex, the dentin surface was covered by heavy coherent deposits of smear layer and debris with irregular shapes and sizes, and the dentinal tubules were not visible in all groups, with the exception of tooth irrigated with $5.25 \% \mathrm{NaOCl}$ at $37^{\circ} \mathrm{C}$ delivered with the $\mathrm{EV}$ system. The $\mathrm{EV}$ group was the only group that at $1 \mathrm{~mm}$ showed the root canal to be cleaner than in the other groups; the mean score was significantly reduced $(20 \%, P<.05)$ when compared with that of the negative control group. At $3 \mathrm{~mm}$ from the apex, the EA and EV showed statistically significant differences when compared with the negative control group (34\% and 24\%, respectively). The EA also showed statistically significant differences compared with PUI and the positive control group. When the samples were exposed to $\mathrm{NaOCl}$ with sonically driven activation, the effect of $\mathrm{NaOCl}$ on the dentinal surface was enhanced, and some of the dentinal tubules were partially opened, with some removal of the smear layer. As the 3 corrections showed, the differences between the negative control (CTR-) and EA (1.5566), CTR - and EV (1.1154), the positive control (CTR+) and EA (1.1912), and EA and PUI $(-1.0523)$ were statistically significant, at least at the 0.05 level, whereas the other differences were not significant. At $5 \mathrm{~mm}$ from the apex, the EV, EA, and PUI showed statistically significant reductions of debris when compared with the negative control group (40\%, $40 \%$, and $28 \%$, respectively). EV and EA showed statistically significant differences with the positive control group, and the 2 irrigating systems enhanced smear layer removal by $30 \%$. The 3 corrections showed a difference between CTR - and EA (1.8688), CTR- and EV (1.9145), CTR - and PUI (1.3034), and CTR+ and EV (1.2222), all of which are statistically significant, at least at the 0.05 level. Finally, at $8 \mathrm{~mm}$ from the apex, it was shown that all the techniques were efficient in improving root canal cleanliness. Moreover, all groups showed increased smear layer removal, moving apically to coronally (Table 2). There was agreement in the differences between the means of CTRand CTR+ (1.3365), CTR - and EA (2.0498), CTR - and EV (1.8504), and CTR - and PUI (1.5727); the other differences were minor and not statistically significant.

\section{Discussion}

The aim of this study was to evaluate the effectiveness of different irrigating systems in removing the smear layer from endodontic walls from the apex to the coronal third. An in vitro closed-end canal model was used because it more accurately simulates in vivo conditions such as gas entrapment in the root canal and periodontal ligament (14). The removal of the smear layer is usually accomplished by irrigants capable of dissolving both organic and inorganic components $(17,23)$. The recommended combination is a final rinse of $15 \%$ or $17 \%$ EDTA solution followed by $1 \%-6 \%$ of $\mathrm{NaOCl}(4,11)$. However, there is no consensus on volume $(18,24)$, time of application $(15,25)$, or activation method $(26,27)$ of irrigating solutions. Recently, different irrigation delivery and activation systems have been proposed to increase both flow and distribution within the root canal system (16). In our study, to increase volume exchange of irrigants at the WL, groups were shaped to a ProTaper F4 (apical size .40, taper 6\%) (28). For improved irrigant delivery at the apical third level, apical patency was confirmed (29) after each instrumentation. Analyses of the 4 distances from the apex showed that the EA performed significantly better than the control groups at 5 and $8 \mathrm{~mm}$ from the apex and a significant increase of smear layer removal when compared with control groups and PUI at $3 \mathrm{~mm}$ from the apex. Similar results were described by Rodig et al (30), who showed significantly greater smear layer removal when the EA was used rather than ultrasonic agitation and 
Basic Research-Technology

TABLE 2. Cleanliness of Root Canals Treated with Different Methods Expressed as the Mean Score

\begin{tabular}{|c|c|c|c|c|c|c|c|c|c|c|}
\hline & \multicolumn{2}{|c|}{ CTR- } & \multicolumn{2}{|c|}{ CTR+ } & \multicolumn{2}{|c|}{$\mathrm{EA}$} & \multicolumn{2}{|c|}{ EV } & \multicolumn{2}{|c|}{ PUI } \\
\hline & Mean & SD & Mean & SD & Mean & SD & Mean & SD & Mean & SD \\
\hline $1 \mathrm{~mm}$ & $4.92^{a}$ & 0.28 & 4.50 & 0.76 & 4.41 & 0.87 & $3.94^{a}$ & 0.99 & 4.56 & 0.70 \\
\hline $3 \mathrm{~mm}$ & $4.62^{\mathrm{bc}}$ & 0.77 & $4.25^{d}$ & 0.71 & $3.06^{\text {bde }}$ & 0.83 & $3.5^{c}$ & 1.04 & $4.11^{\mathrm{e}}$ & 0.96 \\
\hline $5 \mathrm{~mm}$ & $4.69^{f g h}$ & 0.75 & $4.00^{\mathrm{il}}$ & 0.76 & $2.82^{\mathrm{fi}}$ & 0.73 & $2.78^{\mathrm{gl}}$ & 0.55 & $3.39^{h}$ & 0.98 \\
\hline $8 \mathrm{~mm}$ & $4.46^{\mathrm{mnop}}$ & 1.05 & $3.13^{m}$ & 0.64 & $2.41^{n}$ & 0.51 & $2.61^{\circ}$ & 0.50 & $2.89^{p}$ & 0.76 \\
\hline
\end{tabular}

SD, standard deviation.

Different superscript letters indicate different groups $(P<.005)$.

a canal brush. Conversely, these results are in contrast to those from a recent study reporting no significant improvement of smear layer removal with the EA (31). These findings might be attributed to the lower volume of irrigant used (ie, $1 \mathrm{~mL} 17 \%$ EDTA and $3 \mathrm{~mL} 4 \% \mathrm{NaOCl}$ ) compared with the present study in which $17 \%$ EDTA and $5.25 \% \mathrm{NaOCl}$ were used for longer times and at higher volumes. Ultrasonics showed poor results in the apical third ( 1 and $3 \mathrm{~mm}$ from the apex), which is in agreement with previous authors (15), possibly because of the reduced time of activation ( 1 minute) and the contact between the ultrasonic file and the canal walls $(32)$. Conversely, other studies $(33,34)$ have shown that the activation of different concentrations (3\% and 5\%) of $\mathrm{NaOCl}$ with PUI for a period of time from 3 to 5 minutes is sufficient to completely remove the smear layer in instrumented root canals. Some authors showed that files and ultrasonic activation are not efficient in removing the smear layer in straight root canals when using a final flush of $17 \%$ EDTA (27). In our research protocol, PUI showed a reduced ability to remove the smear layer along endodontic walls from apex to crown. These findings are confirmed by a recent study reporting better results with the EV and manual activation than with PUI and passive irrigation (35). In our study, the difference of smear layer removal at 5 and $8 \mathrm{~mm}$ from the apex between PUI and EV was not statistically significant, but both devices performed significantly better than the control groups. The EV system was introduced in endodontics to solve the air entrapment and irrigant flushing drawbacks at the root end (19). In our study, which is in agreement with the study of Schoeffel (19), the EV system showed the highest degree of cleanliness at $1 \mathrm{~mm}$ from the apex. Nevertheless, the EA system showed similar results, if compared with the EV system, regarding the degree of cleanliness at 3,5, and $8 \mathrm{~mm}$ from the apex. This may be explained by the fact that the EA tip activated $\mathrm{NaOCl}$ only and it was positioned at $2 \mathrm{~mm}$ from the apex, whereas the microcannula of the EV reached the WL, ensuring the irrigating solutions (both $\mathrm{NaOCl}$ and EDTA) were refreshed and eliminating the vapor lock at the apex as confirmed by other studies $(20,21)$.

\section{Conclusion}

Based on the results of this study, the activation/delivering of $5.25 \% \mathrm{NaOCl}$ at $37^{\circ} \mathrm{C}$ with different irrigating systems is not a currently viable technique for the consistent removal of the smear layer from endodontic walls. Nevertheless, the EV and EA showed statistically significant results at $1,3,5$, and $8 \mathrm{~mm}$ and 3,5, and $8 \mathrm{~mm}$ from the apex, respectively, thus showing how combinations of activation/delivery systems may help in straightforward clinical protocols. Further methodologically sound in vivo investigations of irrigating solutions and activation/delivery systems are needed for an appropriate evaluation of the cleanliness of endodontic canals.

\section{Acknowledgments}

The authors thank Dr Francesco Basoli, Department of Chemical Science and Technology, University of Rome "Tor Vergata,"
Rome, Italy, for his support in field emission scanning electron microscopic imaging and analyses.

The authors deny any conflicts of interest related to this study.

\section{References}

1. Örstavik D, Pitt Ford TR. Essential Endodontology: Prevention and Treatment of Apical Periodontitis, 2nd ed. Ames, IA: Blackwell Munksgaard Ltd; 2008:1.

2. Shilder H. Cleaning and shaping the root canal. Dent Clin North Am 1974;18: 269-96.

3. Heard F, Walton RE. Scanning electron microscope study comparing four root canal preparation techniques in small curved canals. Int Endod J 1997;30:323-31.

4. Peters CA, Barbakow F. Effect of irrigation on debris and smear layer on canal walls prepared by two rotary techniques: a scanning electron microscopic study. J Endod 2000;25:6-10.

5. Örstavik D, Haapasalo M. Disinfection by endodontic irrigants and dressings of experimentally infected dentinal tubules. Endod Dent Traumatol 1990;6:142-9.

6. White RR, Goldman M, Lin PS. The influence of the smeared layer upon dentinal tubule penetration by endodontic filling materials (part II). J Endod 1987;13:369-74.

7. Kennedy WA, Walker WA, Gough RW. Smear layer removal effects on apical leakage. J Endod 1986;12:21-7.

8. Saunders WP, Saunders EM. The effect of smear layer upon the coronal leakage of gutta-percha fillings and a glass ionomer sealer. Int Endod J 1992;25:245-9.

9. Zehnder M. Root canal irrigants. J Endod 2006;32:389-98.

10. Carson KR, Goodell GG, McClanahan SB. Comparison of the antimicrobial activity of six irrigants on primary endodontic pathogens. J Endod 2005;31:471-3.

11. Ciucchi B, Khettabi M, Holz J. The effectiveness of different endodontic irrigation procedures on the removal of the smear layer: a scanning electron microscopic study. Int Endod J 1989;22:21-8.

12. Munoz HR, Camacho-Cuandra K. In vivo efficacy of three different endodontic irrigation systems for irrigant delivery to working length of mesial canals of mandibular molars. J Endod 2012;38:445-8.

13. Villas-Boas MH, Bernardineli N, Cavalini Cavenago B, et al. Micro-computed tomography study of the internal anatomy of mesial root canals of mandibular molars. J Endod 2011;37:1682-6.

14. Tay FR, Gu LS, Schoeffel GJ, et al. Effect of vapor lock on root canal debridement by using a side-vented needle for positive-pressure irrigant delivery. J Endod 2010;36:745-50.

15. Gu LS, Kim JR, Ling J, et al. Review of contemporary irrigant agitation techniques and devices. J Endod 2009;35:791-804.

16. de Gregorio C, Estevez R, Cisneros R, et al. Effect of EDTA, sonic and ultrasonic activation on the penetration of sodium hypochlorite into simulated lateral canals: an in vitro study. J Endod 2009;35:891-5.

17. Weller RN, Brady JM, Bernier WE. Efficacy of ultrasonic cleaning. J Endod 1980;6: $740-3$.

18. Ahmad M, Pitt Ford TJ, Crum LA. Ultrasonic debridement of root canals: acoustic streaming and its possible role. J Endod 1987;13:490-9.

19. Schoeffel GJ. The EndoVac method of endodontic irrigation: part 2 - efficacy. Dent Today 2008;27. 82, 84, 86-87.

20. Nielsen BA, Baumgartner CJ. Comparison of the EndoVac system to needle irrigation of root canals. J Endod 2007;33:611-5.

21. Desai P, Himel V. Comparative safety of various intracanal irrigation systems. J Endod 2009;35:545-9.

22. Hulsmann M, Rummelin C, Schafers F. Root canal cleanliness after preparation with different endodontic handpieces and hand instruments: a comparative SEM investigation. J Endod 1997;23:301-6.

23. Perez-Heredia M, Ferrer-Luque CM, Gonzalez-Rodriguez MP. The effectiveness of different acid irrigating solutions in root canal cleaning after hand and rotary instrumentation. J Endod 2006;32:993-7.

24. Crumpton BJ, Goodell GG, McClanahan SB. Effects on smear layer and debris removal with varying volumes of $17 \%$ REDTA after rotary instrumentation. J Endod 2005;31:536-8. 


\section{Basic Research-Technology}

25. Teixeira CS, Felippe MC, Felippe WT. The effect of application time of EDTA and $\mathrm{NaOCl}$ on intracanal smear layer removal: an SEM analysis. Int Endod J 2005;38: 285-90.

26. Sabins RA, Johnson JD, Hellstein JW. A comparison of the cleaning efficacy of short term sonic and ultrasonic passive irrigation after hand instrumentation in molar root canals. J Endod 2003;29:674-8.

27. Chopra S, Murray PE, Namerow KN. A scanning electron microscopic evaluation of the effectiveness of the F-file versus ultrasonic activation of a K-file to remove smear laver. J Endod 2008;34:1243-5.

28. de Gregorio C, Arias A, Navarrete N, et al. Effect of apical size and taper on volume of irrigant delivered at working length with apical negative pressure at different root curvatures. J Endod 2013;39:119-24.

29. Vera J, Hernandez EM, Romero M, et al. Effect of maintaining apical patency on irrigant penetration into the apical two millimeters of large root canals: an in vivo study. J Endod 2012;38:1340-3.
30. Rodig T, Dollmann S, Konietschke F, et al. Effectiveness of different irrigant agitation techniques on debris and smear layer removal in curved root canals: a scanning electron microscopy study. J Endod 2010;36:1983-7.

31. Uroz-Torres D, Gonzalez-Rodriguez MP, Ferrer-Luque CM. Effectiveness of the EndoActivator System in removing the smear layer after root canal instrumentation. J Endod 2010;36:308-11.

32. Lee SJ, Wu MK, Wesselink PR. The efficacy of ultrasonic irrigation to remove artificially placed dentin debris from different-sized simulated plastic root canals. Int En$\operatorname{dod} \mathrm{J}$ 2004:37:607-12.

33. Alacam T. Scanning electron microscope study comparing the efficacy of endodontic irrigating systems. Int Endod J 1987;20:287-94.

34. Cameron JA. The use of ultrasonics in the removal of the smear layer: a scanning electron microscope study. J Endod 1983;9:289-92.

35. El-Din Saber S, Hashem AA. Efficacy of different final irrigation activation techniques on smear laver removal. J Endod 2011;37:1272-5. 